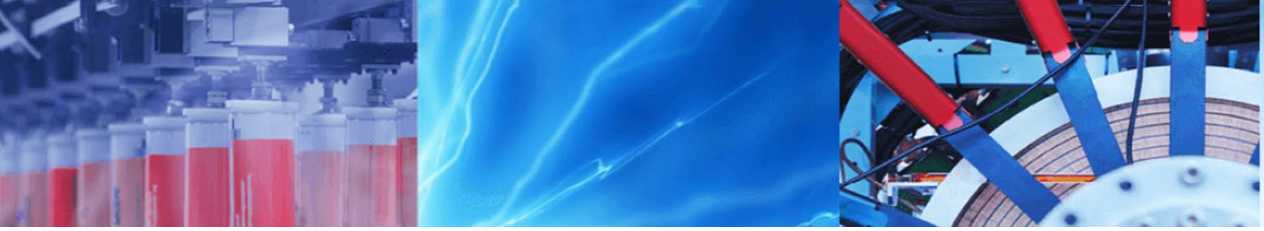

Research Article

\title{
Social vulnerability of smallholder farmers to climate change in Zambia: the applicability of social vulnerability index
}

\author{
William Kwadwo Dumenu ${ }^{1,2} \cdot$ Xavier Takam Tiamgne $^{3}$
}

Received: 25 June 2019 / Accepted: 10 February 2020 / Published online: 18 February 2020

(c) Springer Nature Switzerland AG 2020

\begin{abstract}
This study assesses social vulnerability and coping strategies of smallholder farmers in two districts in Zambia and the applicability of the social vulnerability index (SVI) approach. Household data from 194 households were collected for the assessment of vulnerability and coping strategies. Using six demographic, economic and social indicators, farmers in Chirundu district were found to be more vulnerable to climate change than those in Masaiti district having recorded SVI of 0.47 and 0.41 , respectively. Economic factors (low income level; less diversified sources of income) and social factors (low level of ownership of radio or television; low level of access to climate change information) influenced the vulnerability level of farmers in Chirundu district. Most engaged coping strategies were planting of drought tolerant species, varying the timing of planting, crop diversification, reliance on government assistance and engagement in non-farm jobs. The study makes practical recommendations on how to improve adaptive capacity and resilience of smallholder farmers against climate change impacts. To help tailor the SVI approach for placed-based assessment of social vulnerability to climate change, the paper concludes with recommendations on validity, interrelationships, weighting and aggregation of indicators and scale of application (spatial and temporal) regarding the development and use of SVI.
\end{abstract}

Keywords Climate change $\cdot$ Social vulnerability $\cdot$ Applicability $\cdot$ Adaptation $\cdot$ Zambia

\section{Introduction}

Climate change remains one of the critical issues affecting Zambia's socio-economic development. Drought and dry spells, seasonal and flash floods and extreme temperatures are climate change impacts that the country is experiencing with adverse consequences for food and water security, water quality, energy and sustainable livelihoods of rural communities $[29,34]$. In terms of sectoral impact, agriculture, forestry and water are the most affected [21, 33]. Climate change effect in the agricultural sector alone leaves $60 \%$ of the Zambian population vulnerable and in danger of livelihood insecurity [33]. Smallholder farmers on whose shoulders the Zambian agricultural sector rests would be adversely affected. Climate change impact is also felt in the three agro-ecological regions (AER) of Zambia with each of the regions experiencing a set of peculiar impacts. AER I and II are highly vulnerable to frequent climate-induced drought [32. As a result, suitable arable area for staple food production of these two agro-ecological regions has shrunk by $80 \%$ and has become drier due to decline in annual rainfall of $58 \mathrm{~mm}$ (6\%) [33]. AER III is vulnerable to flooding with potential consequences for crop loss due to waterlogging and run-off.

In spite of the stark reality of climate change in Zambia, the country is ranked as 59th least ready and 37 th most vulnerable among the countries assessed in 2017 by the Notre Dame's ND-GAIN Index Country Rankings [35].

$\triangle$ William Kwadwo Dumenu, wdumenu@csir-forig.org.gh; kdumenu@gmail.com | ${ }^{1}$ Forestry Research Institute of Ghana, P. O. Box UP 63, Kumasi, Ghana. ${ }^{2}$ Environmental Economics and Resource Management, University of Freiburg, Tennenbacher Str. 4, 79106 Freiburg, Germany. ${ }^{3}$ School of Natural Resource, The Copperbelt University, P. O. Box 21692, Kitwe, Zambia. 
Therefore, in the effort to addressing climate change issues in Zambia, the Environmental Council of Zambia (ECZ) has conducted a number of studies to assess the vulnerability of all sectors (e.g. forestry, agriculture, water, health) and potential adaptation to climate change [21]. The aim is to understand the magnitude of the threat posed by climate change and determine effective adaption or mitigation measures. However, these studies focused on the threat of biophysical factors without considering the social dimensions of climate change vulnerability which is critical in determining the level of vulnerability within a community or country. Adger et al. $[2,3]$ have highlighted the deficiency of impact-driven (biophysical) vulnerability assessment in determining and explaining the underlying causes of vulnerability of different social groups. Hence, it is worth noting that vulnerability of populations to climatic conditions cannot be solely understood through the quantification of biophysical impacts, but that both physical and social factors interact to characterize a system's vulnerability to climate change $[1,58]$. Therefore, understanding the impacts of climate change is inseparably linked with the human conditions that create resilience or vulnerability to that event [40]. Assessing social dimensions of climate change vulnerability is crucial to identifying the social, economic, demographic, institutional and political factors that influence vulnerability or resilience to climate change and variability. Such knowledge helps in ascertaining options that promote or constraint adaptation or mitigation measures [28]. It also informs policymakers in devising interventions that can help households and communities to improve their capacities to adapt to climate change impacts and reduce their vulnerability.

Despite the relevance of assessing the social dimensions of climate change vulnerability, no study has assessed the underlying socio-economic and demographic factors that influence social groups, households and communities' vulnerability to climate change in Zambia. This study fills this gap by assessing the social vulnerability of smallholder farmers to climate change in two districts in Zambia using the social vulnerability index (SVI) approach. It subsequently discusses the applicability of the SVI approach in relation to indicator selection and validity, weighting, and aggregation and scale of application (spatial and temporal). In addition, the study identifies locally evolved coping strategies to climate change to demonstrate how smallholder farmers cope with climate change impacts. The results of this study illustrate how policymakers can identify where actions may be taken to reduce vulnerability and help social groups and communities overcome the challenges they face in implementing adaptation strategies and enhancing their adaptive capacity. The perspective shared on the applicability of the SVI approach contributes to ensuring the best use of the approach for placed-based social vulnerability assessment. It is envisaged that results from this seminal work on social vulnerability in Zambia will inspire further research on social dimensions of climate change vulnerability in Zambia to help generate well-informed policies and interventions that address the underlying factors of vulnerability.

\section{Concept and definition: social vulnerability to climate change}

The Intergovernmental Panel on Climate Change (IPCC) defines vulnerability as the degree to which a system is susceptible to or unable to cope with adverse effects of climate change, including climate variability and extremes. It is a function of the character, magnitude and rate of climate variation to which a system is exposed, its sensitivity and adaptive capacity [27]. Exposure refers to the direct danger (i.e. the stressor), and the nature and extent of changes to climate variables (e.g. temperature, rainfall, extreme weather events). Sensitivity describes the human-environmental conditions that determine the response of a given system to climate change. These conditions moderate the nature of the impact of the stressor. Adaptive capacity relates to the potential to implement adaptation measures that help avert potential impacts [23]. Exposure as a component of vulnerability relates to changes in the climate itself, while the remaining components, sensitivity and adaptive capacity are about the properties [38] or the inherent characteristics of the system being exposed to the stressor [46]. The proprieties, inherent characteristics, state or condition of the system, people or social groups exposed to climate change are largely influenced by livelihood characteristics [46], access to economic resources, access to information, infrastructural development, institutions, kinship network, literacy levels, skills, equity and political influence $[7,47]$ and ecological conditions [20]. Vulnerability to climate change varies greatly among regions, sectors and social groups due to climatic and geographic heterogeneity, and differences in physical and social factors that influence a system or people's adaptive capacity.

Consequently, vulnerability has both physical and social dimensions. The physical dimension of vulnerability relates to exposure and is a measure of the natural hazard or environmental stressor(s) [57]. Social dimension of vulnerability termed 'social vulnerability' $[5,28]$, 'contextual vulnerability' [38] or 'second generation adaptation research' [9] focuses on the capacity or pre-existing state of the system and is related to the socio-economic, demographic and institutional factors that characterize the capacity of the system, population or individuals $[8,44,49,50]$. Blaikie 
et al. [5] also asserted that vulnerability to natural hazard has a social component (social vulnerability) which is determined by socio-economic factors such as income distribution, assets, ethnicity, gender, poverty and source of livelihood. Following this understanding and characterization of social vulnerability, this paper adopts Dumenu and Obeng [15] definition of social vulnerability to climate change as the degree to which a system is susceptible to the effects of climate change due to the interaction of socio-economic and demographic factors. Accordingly, this study integrates demographic, economic and social factors to assess social vulnerability to climate change through a set of indicators that represent the factors of social vulnerability. It is expressed below:

$\mathrm{SV}=f \cdot\left[\frac{1}{n}(\mathrm{DF}+\mathrm{EF}+\mathrm{SF})\right]$

where SV is social vulnerability, DF is demographic factors, $\mathrm{EF}$ is the economic factors and SF is social factors, and $n$ is number of social vulnerability factors.

\subsection{Social vulnerability to climate change: determining factors and indicators}

Thus far, it is clear that vulnerability to climate change has social dimensions and is characterized by economic, social, demographic, institutional and political factors $[13,23,28$, $53,54]$. Dwelling on three of the factors (economic, demographic and social) influencing social vulnerability to climate change, the theoretical arguments and assumptions relating to the factor-vulnerability functional relationship, and their respective indicators are elaborated below and presented in Table 1.

Economic factors: there is consensus that strong economy acts as a safety net in the case of environmental risk and hazard exposure, both pre-event through enabling anticipatory coping strategies and post-event in responding to a shock $[8,10]$. Thus, communities, households and individuals with strong economic situation display resilience in case of environmental risk and exposure by drawing on other resources to maintain their livelihoods and cope with the adverse effects of the hazardous events. Their strong economic situation enables them to develop their anticipatory adaptive capacity to reduce their vulnerability. On the other hand, those with limited economic entitlements have very limited or very narrow range of alternatives to enhance their capacity to withstand adverse effects of environmental risks such as climate change. This renders them less resilient and more vulnerable to environmental risk and exposure. Also, economic activities that are highly dependent on climate-sensitive production and heavily reliant on natural resources are particularly vulnerable to environmental shocks $[45,53]$. Indicators such as occupation, type of economic activities, material wealth and income are used in assessing economic factors that contribute to climate change vulnerability or resilience of communities, households or individuals. In this study, diversified sources of income and household income level are used as indicators of economic factors to assess its contribution to climate change vulnerability.

Diversified sources of income has been shown to improve people's capacity in the time of crisis since it provides some form of welfare insurance against shocks [15]. Because their livelihood is derived from different income sources, it minimizes their exposure to the impacts of adverse events such as climate change. The greater the diversity of income sources, and the variability of those income sources across time, the greater the resilience of livelihood to disruptions [1]. On the other hand, dependence on a narrow range of income sources is an element of vulnerability [1]. Income level of households or individuals also influences vulnerability. High income level provides economic security and stability; hence, the ability to draw on alternative entitlements and access resources in the face of shock which in turn enhances their resilience. Low income level is associated with low-paying jobs which most often are unstable means of employment [31]. These may include domestic service jobs (house cleaning, yard work, child-care), petty trading, etc. In times of crisis or shocks, these jobs are lost or considerably reduced owing to lowering of income of those needing such services [30]. Thus, households or individuals with low income levels are unable to secure their livelihood in times of shock thereby increasing their vulnerability to environmental stressors such as climate change $[15,59]$.

Demographic factors: the structure and composition of populations as characterized by age, household size, dependency ratio, literacy, gender, proportion of population that is economically active, etc. are found to influence the resilience or vulnerability to climate change. For example, a population of high proportion of economically active ones are able to engage in productive economic activities, access additional and or alternative livelihood options, and improve their income level to enhance their adaptive capacity in case of stress resulting from climate change and variability. This study uses household size and literacy as indicators to assess demographic factors that contribute to climate change vulnerability.

Households with large number of dependents often direct larger proportion of their resources (finance, time) towards the welfare of the household members $[5,37$, $43,59]$, leaving them with little resources to access additional and or alternative livelihood options to enhance their capacity against the impact of climate change and variability. High level of literacy reduces vulnerability by increasing the ability to access and understand climate 


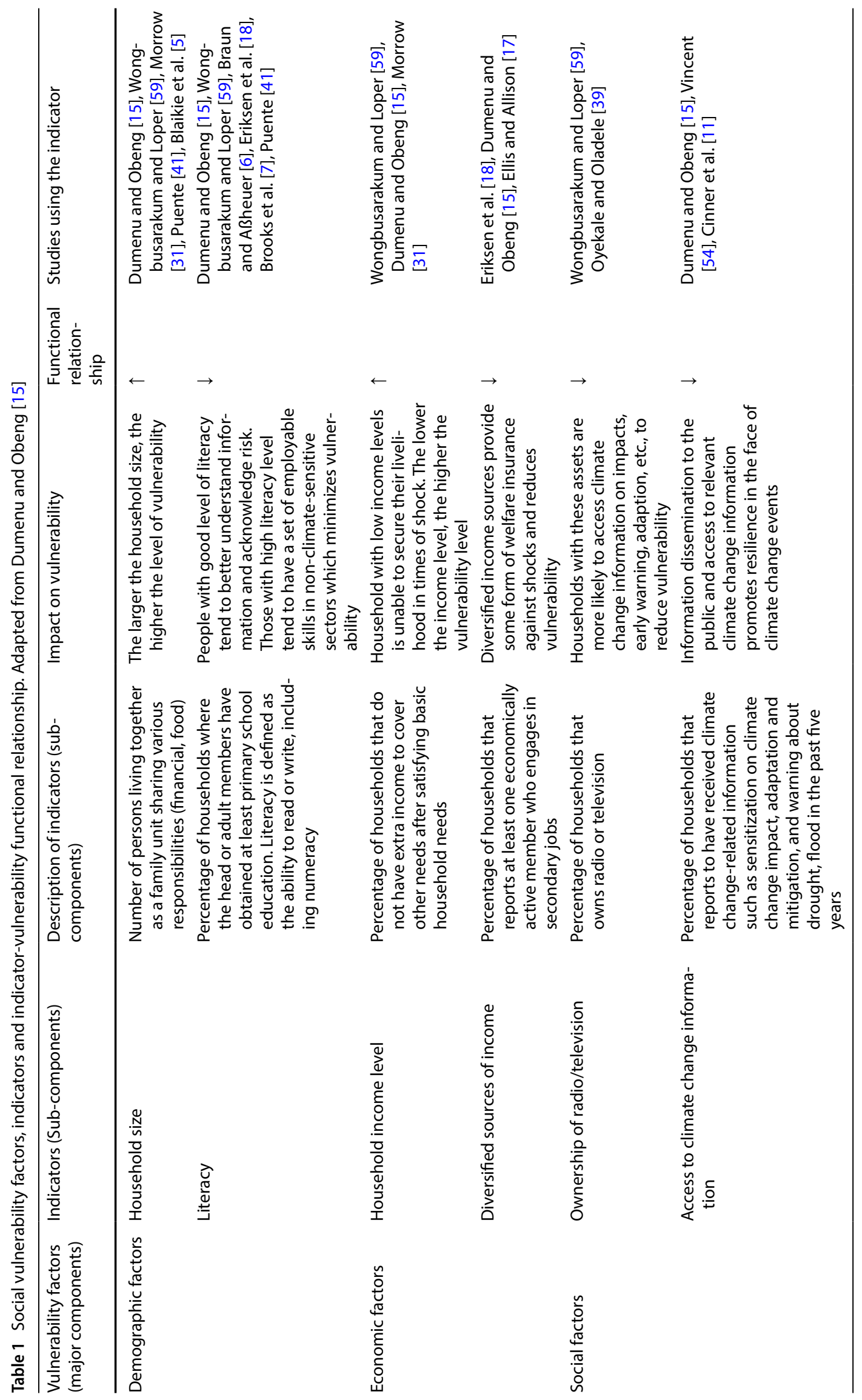


events and impact-related warning, adaption and recovery information $[7,41]$. Also, high educational attainment provides the prospects of high earnings, and employability in non-climate-sensitive jobs which reduces vulnerability to climate change and variability $[6,7,31]$. Lower level of education constrains the ability to understand warning information and access to recovery information.

Social factors: these are factors related to beliefs, social networks and ethnicity that influence the thought, choices and behaviour of individuals, groups or communities [15], and are interrelated. For instance, beliefs may be influenced by access to information, while social networks that persons or households belong as well as ownership and use of media gadgets may influence the channel of information delivery and access to information. Besides, before, during and after exposure to environmental stressors, social networks serve as sources for social and economic support. All these factors impact on the capacity of individuals, households or communities' respond to climate change and variability. To assess the influence of social factors to climate change vulnerability, ownership of media gadgets such as television or radio, and access to climate change information were used as indicators in this study.

Access to information and communication infrastructure influences vulnerability [5] and helps build communities' adaptive capacity [11]. Televisions and radios serve as an access point to information related to climate change impacts, early warning and adaptation options. The use of these devises does not require high levels of literacy or formal education, hence their role in mediating vulnerability across a range of persons, households or social groups. Ownership of media devises alone is not enough to mediate vulnerability. Access to specific information on climate change such as early warning and adaptation or coping measures substantially reduces vulnerability in the face of environmental stressors. Accessing climate change information whatever form it may be essentially build the adaptive capacity of individuals, households and communities exposed to climate change and variability.

\section{Methodology}

\subsection{Study area}

The study was conducted in two districts namely, Chirundu and Masaiti located in agro-ecological regions I and III, respectively (Fig. 1). Chirundu is located in the Lusaka province, while Masaiti is located in the Copperbelt province. These areas were selected for the study because of their contrasting climatic features (semi-arid/humid-wet) and livelihood characteristics. Chirundu located in AER I is characterized by very hot weather with temperatures reaching about $50^{\circ} \mathrm{C}$ in summer and a low average annual rainfall of less than $800 \mathrm{~mm}[19,24]$. The district thrives on agriculture and tourism. AER I (the region where Chirundu is located) is semi-arid, and its temperatures tend to be higher than elsewhere in the country. The main livelihood activities in the region include cereal production, fishing along main rivers, animal rearing and tourism in parks and lakes located within the region. The quantity and quality of market infrastructure and general physical access within the zone are generally less well-developed compared with other parts of the country [19].

Masaiti district located in AER III is characterized by high annual rainfall $(1000-1500 \mathrm{~mm})$. It has a tropical climate with two distinct seasons, the rainy season and the dry season. The district experiences an annual mean maximum temperature of $29.5^{\circ} \mathrm{C}$ and annual mean minimum temperature of $12.1^{\circ} \mathrm{C}$. Agriculture and mining are the main occupation of the people in the area. AER III (the region where Masaiti is located) is home to the mineralrich Copperbelt province which drives a strong labour and trade economy around the mining areas. The vast forest resources and plantations also contribute to an active timber industry. Livelihoods in this region vary, but depend primarily on cereal and cassava production, mining, trade and fishing [19].

\subsection{Data collection and analysis}

Data for the assessment of social vulnerability and coping strategies were collected from a total of 194 respondents in nine [8] agricultural camps located in nine [8] wards. Hundred (100) respondents were selected in Masaiti district, while ninety-four (94) were selected in Chirundu district. In selecting the respondents, a two-stage sampling method was used. At the first stage, the wards in each district were stratified into agricultural blocks. Upon stratification, five [4] agricultural camps in Masaiti district (Masaiti, Mambwe Misinge, Mipundu, Nyenyezi and Katuba camps) and four [3] agricultural camps in Chirundu district (Chirundu, Siangwemu, Sikoongo and Lusitu Bridge camps) were randomly selected. At the second stage, purposive sampling was used to select twenty [20] respondents each in the five [4] camps in Masaiti district. In Chirundu district, twenty-five [26] respondents in Chirundu and Siangwemu camps, 24 and 20 respondents in Sikoongo and Lusitu Bridge camps were selected respectively. This resulted in a total of 194 respondents. The purposive sampling was to ensure that respondents aged 35 years and above who have experienced long-term changes in the climate including its impacts were captured for interview.

Questionnaires, interviews and focus group discussions were used in collecting data for the assessment of social 


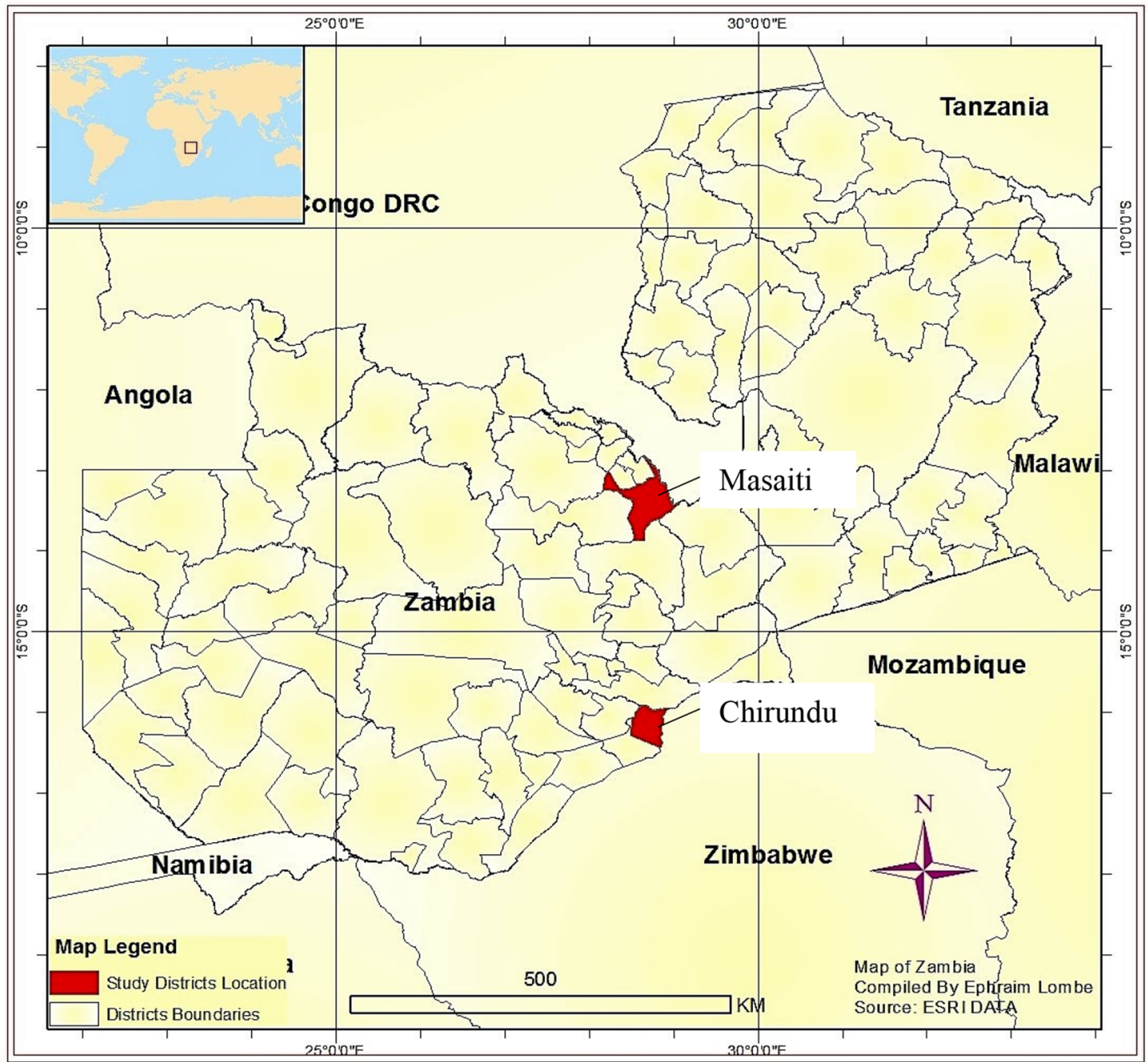

Fig. 1 Study areas

vulnerability and coping strategies. The questionnaire survey focused on gathering information on climate change impacts and coping/adaptation strategies. Questions such as 'compared to the past 10 years, have you noticed any changes in temperature, and the timing and frequency of rainfall; how have you been affected by these changes; what measures have you adopted to cope with the effects of climate change' were asked to identify the impacts of climate change and adaptation strategies. Additionally, the interviews and questionnaire survey also sought information on demographic and socio-economic factors such as: household size, literacy, access to climate change information, diversified sources of income, level of income and ownership of media devices such as radio and television. These formed the basis for the assessment of the level of social vulnerability of smallholder farmers in the two districts. Consent of respondents was sought before conducting the interview. Respondents were informed that they can withdraw their participation at any stage of the interview if they so wish. To ensure anonymization, the questionnaires did not seek any personally identifiable information from the respondents. The interviews were conducted in both English and the native language of the respondents who could not speak and understand English.

Qualitative and quantitative analytical methods were applied in the analysis of the data. Descriptive statistical methods were used in determining literacy, access to information on climate change, household size, diversified sources of income, level of income and ownership of radio or television. Information gathered from respondents was discussed without identifiers. 


\subsection{Assessment of social vulnerability to climate change}

In assessing social vulnerability to climate change, the paper adopted the indicator approach used by Dumenu and Obeng [15]. The indicator approach computes indices based on selected indicators. This approach was used because of its applicability at any scale (household, district, national and global), and its usefulness in developing a better understanding of the socio-economic factors contributing to vulnerability [26]. Based on the extensive literature review, six indicators were selected to assess social vulnerability of the districts. The indicators include household size, literacy level, diversified sources of income, level of income, access to climate change information and ownership of radio or television. The vulnerability factors constituted major components of the social vulnerability index, while the indicators constituted the sub-components. Table 1 presents the social vulnerability factors, their respective indicators as well as their functional relationship to climate change.

\subsection{Estimating social vulnerability index}

To determine social vulnerability of the smallholder farmers in the two districts, indicators for the vulnerability factors (demographic, economic and social factors) were measured in their respective units. The measured indicators were then standardized to make them comparable as an index. In standardizing the units, the functional relationships between variables and vulnerability were considered (Table 1). When vulnerability increases with increase in the value of an indicator, an upward $\uparrow$ functional relationship is occasioned. Therefore, the higher the value of an indicator, the higher the vulnerability. Downward $\downarrow$ functional relationship occurs if vulnerability decreases with increase in value of the indicator.

When the variable has upward $\uparrow$ functional relationship with vulnerability, normalization was done using Eq. (2):

$X_{i j}=\frac{X_{i}-\operatorname{Min} X_{j}}{\operatorname{Max} X_{j}-\operatorname{Min} X_{j}}$

When the variable has downward $\downarrow$ functional relationship with vulnerability, normalization was done using the formula:

$X_{i j}=\frac{\operatorname{Max} X_{j}-X_{i}}{\operatorname{Max} X_{j}-\operatorname{Min} X_{j}}$

where $X_{i j}$ is the standardized value of each indicator of the factors for a district $j, X_{i}$ is the actual value of the indicator for the respective factors, $\operatorname{Min} X_{j}$ and $\operatorname{Max} X_{j}$ are the minimum and maximum values of the indicator for the district $j$.

For the purpose of creating vulnerability indices for each factor (major components) of social vulnerability for each district, the index values of each indicator (subcomponents) of the factors (major components) were summed up and the average determined. This was done using Eq. (4):

$M_{\mathrm{v}}=\frac{\sum_{i=1}^{2} X_{i j}}{n}$

where $M_{\mathrm{v}}$ is the averaged index value of one of the factors (major components) of social vulnerability, $X_{i}$ is the actual value of the indicator for the district $(j)$, and $n$ is the number of indicators for each social vulnerability factor (major components).

Finally, to determine social vulnerability of the smallholder farmers in the districts, the various indices were substitute into Eq. (1) yielding Eq. (5):

$\mathrm{SV}=f \cdot\left[\frac{1}{n}\left(M_{\mathrm{DF}}+M_{\mathrm{EF}}+M_{\mathrm{SF}}\right)\right]$

where $M_{\mathrm{DF}}$ is the index value of the demographic factors, $M_{\mathrm{EF}}$ is the index value of the economic factors, $M_{\mathrm{SF}}$ is the index value of the social factors and $n$ is the number of social vulnerability factors (major components).

\section{Results and discussion}

\subsection{Social vulnerability to climate change: influencing factors}

The results of the social vulnerability index (SVI) revealed that smallholder farmers in Chirundu district, AER I are more vulnerable to climate change than those in Masaiti district, AER III having recorded SVI of 0.47 and 0.41 , respectively (Table 2). Figures 2 and 3 present the social vulnerability factors (major components) and their respective indicators (sub-components) that influenced the vulnerability of the farmers in the districts. The scale of the diagrams (Figs. 2,3) ranges from 0 (less vulnerable) at the centre of the web/triangle to 1 (most vulnerable) at the outside edge. In terms of social vulnerability factors, economic factors largely influenced high vulnerability level of the farmers in Chirundu district followed by social factors, with demographic factors been the least. Economic and social factors recorded relatively higher indices $(0.72$, 0.43 ) compared to that of farmers in Masaiti district $(0.61$, 0.35) (Table 2, Fig. 2). Low income level, less diversified sources of income and low level of access to radio or TV contributed to the economic and social factors influencing 
Table 2 Indexed sub-components, major components and overall social vulnerability index of smallholder farmers in the two districts

\begin{tabular}{|c|c|c|c|c|c|}
\hline \multirow{2}{*}{$\begin{array}{l}\text { Social vulnerability factors (major } \\
\text { components) }\end{array}$} & \multirow[t]{2}{*}{ Indicators (sub-components) } & \multicolumn{2}{|c|}{ Sub-components indices } & \multicolumn{2}{|c|}{ Major components index } \\
\hline & & $\begin{array}{l}\text { Chirundu } \\
\text { (AER I) }\end{array}$ & Masaiti (AER III) & $\begin{array}{l}\text { Chirundu } \\
\text { (AER I) }\end{array}$ & Masaiti (AER III) \\
\hline \multirow[t]{2}{*}{ Demographic } & Household size & 0.38 & 0.48 & 0.27 & 0.28 \\
\hline & Literacy & 0.17 & 0.08 & & \\
\hline \multirow[t]{2}{*}{ Economic } & Income level & 0.86 & 1 & 0.72 & 0.61 \\
\hline & Diversified sources of income & 0.57 & 0.22 & & \\
\hline \multirow[t]{2}{*}{ Social } & Access to climate change information & 0.37 & 0.52 & 0.43 & 0.35 \\
\hline & Ownership of radio/TV & 0.49 & 0.18 & & \\
\hline Overall social vulnerability index & & & & 0.47 & 0.41 \\
\hline
\end{tabular}

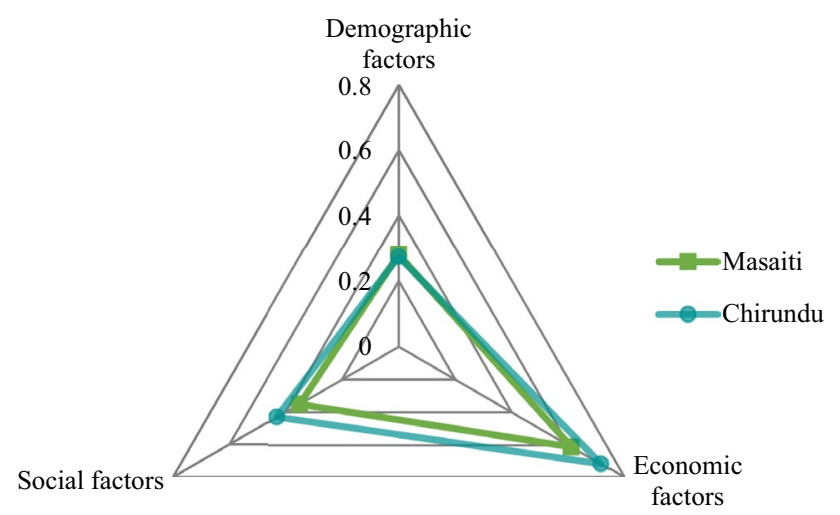

Fig. 2 Distribution of social vulnerability factors (major components)

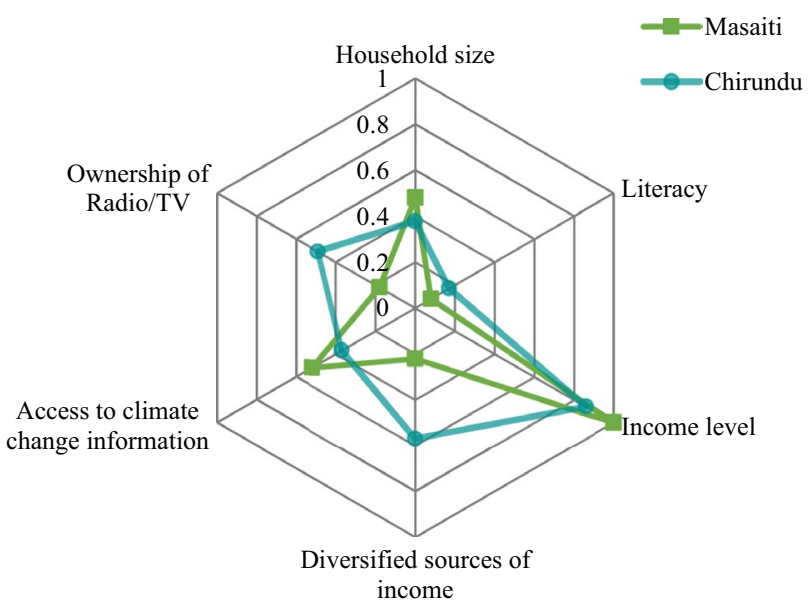

Fig. 3 Distribution of social vulnerability indicators (sub-components)

vulnerability level of smallholder farmers in Chirundu district (Fig. 3).

Demographic factors recorded the lowest index score among the three social vulnerability factors. The index score was similarly low for both Chirundu (0.27) and
Masaiti (0.28) districts (Table 2). The two districts have high literacy level and medium household sizes. In both districts, only $8-17 \%$ of the households had no formal education (Table 2). This is consistent with high literacy levels of the provinces of the respective districts. For instance, the Lusaka province (where Chirundu district is located) and Copperbelt province (where Masaiti district is located) both have adult population literacy of $93.5 \%$, and youth literacy of $96.1 \%$ and $96.6 \%$ respectively $[51,52]$.

In relation to economic factors, Chirundu district recorded higher index score (0.72) than Masaiti district (0.61) (Table 2). However, in terms of contributing factors (sub-components), both districts had relatively low levels of income indicative of index scores of 1 and 0.86 for Masaiti and Chirundu districts, respectively (Table 2). This means large percentage of households in both districts did not have extra income left to cover other expenses after satisfying basic or important household needs. For Masaiti district, the result is particularly interesting in that the district is located in the mineral-rich Copperbelt province which drives a strong labour and trade economy around the mining areas. And so, one would expect that income levels would be high enough to cover extra household needs, hence reducing the vulnerability of smallholder farmers in this region. This finding is similar to that of Gbetibouo and Ringler [22] who found that farming regions in South Africa deemed to be most vulnerable to climate change/variability did not always overlap with the most vulnerable populations. Our results indicate that vulnerability to climate change is indeed socially differentiated by socio-economic characteristics and the particular context of social groupings. This drives home the point that the most vulnerable people may not be in the most vulnerable places [54].

On the other hand, diversified sources of income were significantly limited in Chirundu district (0.57) compared with Masaiti (0.22) (Table 2). Less diversified sources of income coupled with low income level in Chirundu district contributed to its high index score under economic 
factors. Single source or very limited sources of income restrict people to a single or very narrow range of resources from which livelihood can be drawn. Thus, in times of shocks or crisis they are unable to draw on other resources (should the main source of income fail) to secure their needs and minimize the resultant impacts of adverse events such as climate change and variability [18]. Chirundu's local economy is agrarian with its population heavily dependent on rain-fed agriculture. Rain-fed agriculture is a climate-sensitive livelihood activity, and any unfavourable disruption in environmental conditions caused by climate change negatively affects production thus, household income and livelihoods. Depending primarily on farming for household income compromises their livelihood security particularly in times of low crop production, thereby negatively affecting how much food is produced and sold for the well-being of the household. This is illustrated by the prolonged drought event experienced in communities in Chirundu district in 2014/2015 farming season. The drought left over 5000 farmers without livelihood owing to poor maize yield. Government assistance had to be provided to support the affected families. Other families had to engage in firewood collection in an area denuded of tree cover in order to survive. Unsustainable firewood collection as a livelihood activity further degrades the drought-prone region surrounding Chirundu, while further exposing it to climate change effects. Smallholder farmers in Masaiti district had more diversified sources of income indicative of the low index score of 0.22 (Table 2). This might have been due to the effect of the mineral-rich Copperbelt province which drives a strong labour and trade economy within its catchments. Nonetheless, what was intriguing is that, the diversified sources of income did not contribute to improve household income to cover extra household needs upon satisfying the important basic ones. The reason for this may be related to the fact that smallholder farmers in the district had large household sizes (Table 2). Therefore, much of the household income was spent on members of the household leaving very less or no income to cater for rising needs.

Concerning social factors, there were markedly different responses for both districts. Chirundu district recorded a higher index score (0.43) compared with Masaiti district (0.35) (Table 2). Although the index score for access to climate change information was higher for Masaiti (0.52) compared to Chirundu (0.37), the critical indicator contributing to the higher index score for social factors responsible for higher climate change vulnerability level of smallholder farmers in Chirundu district was low level ownership of radio or television. Chirundu district had a small proportion of smallholder farmer population owning these important media gadgets compared with Masaiti's. This is indicative of Chirundu's high index score of 0.49 and Masaiti's low score of 0.18 (Table 2). These gadgets are important means of communication in rural areas for sensitization and dissemination of information on climate change, early warning and adaptation strategies. Donatti et al. [14] point to early warning systems as a technological measure that improves adaptive capacity of farmers. Communication gadgets such as TV and radio serve as means of transmitting information generated for example by early warning systems for the benefit of farmers. Consequently, low availability of radios and TV sets in households limits access to climate change information thus, rendering people more vulnerable to changes and variability in the climate. Vincent [54] pointed out that, limited access to relevant climate change information increases vulnerability. Access to climate change information is critical to developing appropriate and effective response to climate change impacts, hence the need to improve access points to information on climate change in communities or social grouping with low access to radio or television.

\subsection{Coping strategies to climate change}

In the face of changing climate, smallholder farmers in both districts have adopted and devised various strategies to cope with the impacts they experience. As shown in Table 3, the most dominant coping strategies are planting of drought tolerant species (85.4\%), varying the timing of planting $(71.3 \%)$, crop diversification $(62.5 \%)$, reliance on government assistance (45.5\%) and engagement in non-farm jobs (28.5\%). Notably, farming-related coping strategies dominated the non-farming-related strategies. Between the two districts, increasing number of farmers in Chirundu adopted more coping strategies than those in Masaiti. Hamazakaza [25] reported early planting as the most widely applied adaptation practice among farmers in response to variable onset of rainy season in Chirundu district including communities in other provinces. Other adaptation practices engaged by farmers also include staggered planting (planting various crops at different times) in response to unpredictable weather conditions, crop diversification and adoption of drought tolerant varieties [25]. Fumpa-Makano [21] also mentioned provision of government assistance in the form of free fertilizer distribution to subsistence farmers to improve crop yield as a coping strategy promoted against climate change in Zambia. Nonetheless, it is believed such programmes only offer farmers short-term solutions instead of long-term benefits that would result from adoption of sustainable agroforestry practices. Similarly, Nhemachena and Hassan [36] also observed that, common adaptation practices among Zambian farmers against climate change were crop diversification, planting of varieties, varying of planting time and engagement in non-farm activities. 
Table 3 Coping strategies against climate change

\begin{tabular}{llll}
\hline Coping strategies & $\begin{array}{l}\text { Masaiti } \\
(n=100)\end{array}$ & $\begin{array}{l}\text { Chirundu } \\
(n=96)\end{array}$ & $\begin{array}{l}\text { Total } \\
(n=196)\end{array}$ \\
\hline $\begin{array}{l}\text { (a) On farm strategies } \\
\text { Planting late or early to avoid drought }\end{array}$ & $45.8 \%(44)$ & $96.7 \%(88)$ & $71.3 \%(132)$ \\
$\quad$ Planting drought tolerant or resistant varieties & $74 \%(71)$ & $96.7 \%(88)$ & $85.4 \%(165)$ \\
Planting various crops at different times & $55.7 \%(54)$ & $69.2 \%(63)$ & $62.5 \%(117)$ \\
(b) Off-farm strategies & & & \\
$\quad$ Rely on family/friends/neighbours & $20 \%(19)$ & $17.6(16)$ & $18.8 \%(35)$ \\
Receive assistance from the government & $43 \%(41)$ & $47.3 \%(43)$ & $45.2 \%(84)$ \\
Income from off-farm jobs & $36 \%(34)$ & $20.9 \%(19)$ & $28.5 \%(53)$ \\
$\quad$ Sales non-farm assets & $17.4(16)$ & $11 \%(10)$ & $14.2 \%(26)$ \\
\hline
\end{tabular}

In spite of these commendable efforts on the part of farmers to cope with climate change impacts, the measures taken are largely coping strategies that reduce present vulnerabilities without necessarily accounting for future climate change impacts. To increase resilience of communities against future climate change impacts, there should be concerted effort at promoting planned or anticipatory adaptation strategies based on planned studies and research. In this regard, adaptation strategies would be effective at reducing present and future vulnerabilities to climate change and increase resilience.

\subsection{Implication for policy and climate change relevant interventions}

Properly characterizing vulnerability is a key to informing the development of appropriate policy interventions targeted at improving adaptive capacity of vulnerable people or social groups. However, this requires a clear and robust vulnerability assessment framework that can lead to the recommendation of reliable policy interventions. The social vulnerability index used in this study lends itself as a tool or as an assessment framework that can be built on and integrated into national climate change vulnerability assessment. As illustrated in Fig. 4, the framework focuses on assessing the social vulnerability of smallholder farming households to climate change. It develops six indicators for three social vulnerability determining factors namely demographic, economic and social factors. The factors and indicators can be expanded further to include other valid indicators relating to health, food, water, social networks, etc. By applying the social vulnerability index (SVI) using the indicators, the nature (who, what, level) of vulnerability of the subject of interest (e.g. smallholder farmers) is determined. Gaining insight into the nature of vulnerability, coping measures and adaptation measures relevant for policy actions are identified and recommended, and these include crop diversification, promotion of conservation/climate-smart agriculture, etc. The social vulnerability assessment framework (Fig. 4) addresses critical vulnerability and adaptation questions such as: who are vulnerable and why? What conditions and processes moderate vulnerability? How is vulnerability differentiated? At what scales do vulnerability factors or determinants operate? What interventions reduce vulnerability or build resilience?

Following the assessment of the factors contributing to vulnerability of smallholder farmers, specific climate change relevant policy interventions are made below:

\subsubsection{Improve access to and strengthen climate information services}

A critical area for enhancing adaptive capacity and climate change resilience is improving access to relevant climate change information. This involves providing early warning about agriculture-related impacts such as drought and dry spells, onset of rains, coping and adaption strategies (scientific or indigenous knowledge-based) in a manner and language that is clear, comprehensible and practical for intended recipient to act upon. Such an action will constitute a policy response to the low level of access to climate change information, and low level of ownership of radio or TV among vulnerable smallholder farmers in Zambia. In relation to this, there is the need to find innovative ways and improve existing ways to increase access to climate change relevant information. Some of the innovative ways may involve setting up of rural information hubs in the vulnerable communities and airing of specific programmes designated to advance information on seasonal rainfall, drought forecast, recommended best time for planting to avoid crop failure or low yield and other corresponding coping/adaptation strategies for the benefit of farmers as suggested by Dumenu and Obeng [15]. Also, climate change relevant information can be sent to farmers on their registered mobile phone numbers or helpdesk set-up to respond to queries and provide reliable information to farmers via toll-free phone lines. Agricultural extension services should 


\section{UNIT OF ANALYSIS: SMALLHOLDER FARMING HOUSEHOLDS}

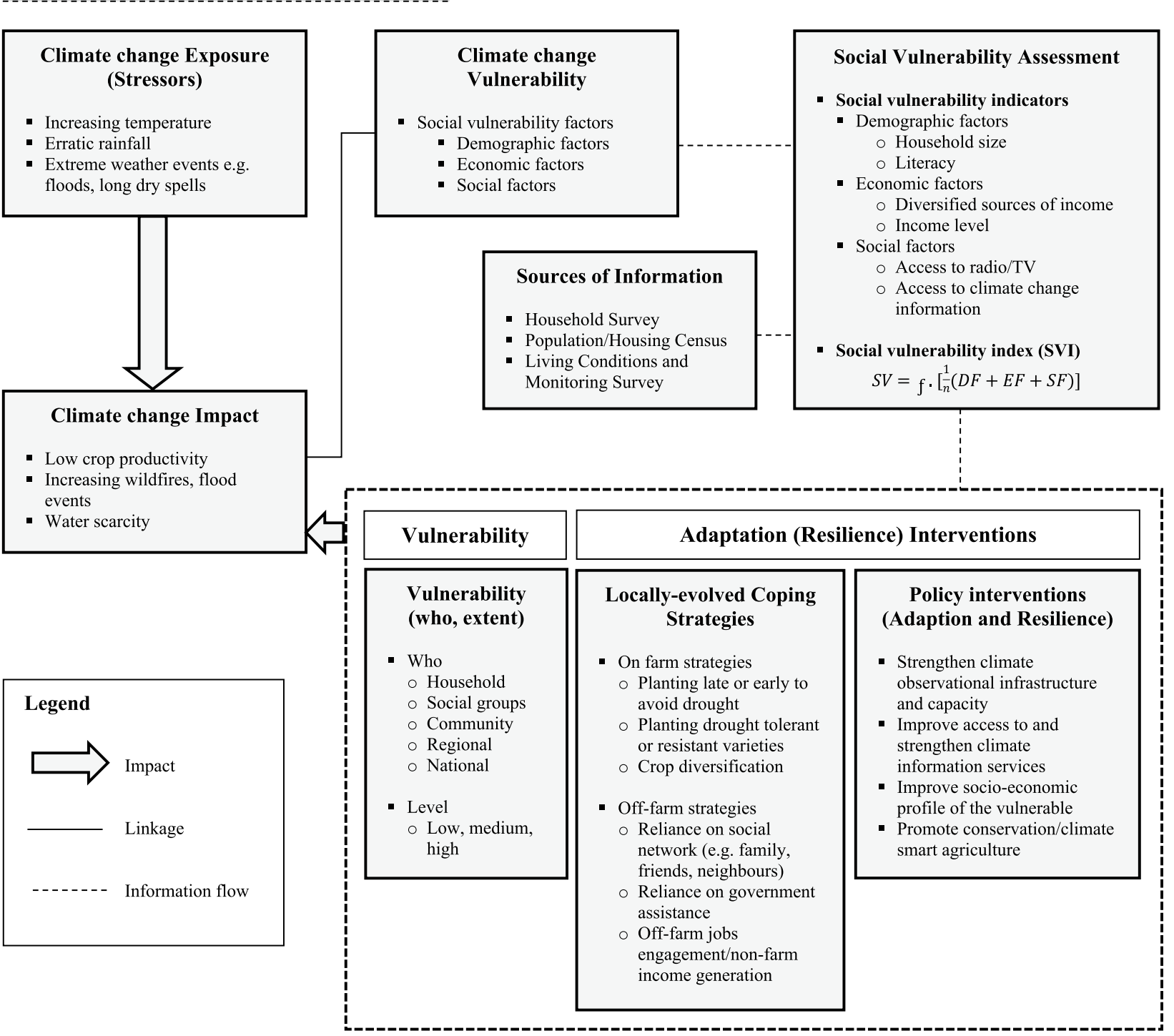

Fig. 4 Social vulnerability assessment framework

also be strengthened and extension officers' capacity built to deliver appropriate advise to farmers on agriculture-related climate change impacts, adaptation and mitigation. Indeed, improving access to climate change relevant information can enable smallholder farmers to plan for and manage climate risk to enhance their adaptive capacity and reduce their vulnerability.

\subsubsection{Strengthen climate observational infrastructure and capacity}

Delivering and disseminating climate change and weather information relevant for improving adaptive capacity of farmers and reducing their vulnerability would require strengthening of climate observational infrastructure and 
capacity. Improved capacity for climate observation will facilitate generation and delivery of information on climate and weather-related information such as onset and end of the rains, dry spells and drought and wind storm and heavy rainfall/waterlogging. Information of this kind is critical for farmers in making informed decisions on timing of field preparation and planting, strategies/techniques for crop development and farm/crop management. Farmers having this information and acting accordingly can make the difference between a productive growing season and one that is not. Additionally, it is essential that inter-sectoral coordination of departments, agencies and ministries responsible for generation and management of climate change and weather-related information such as the Disaster Management and Mitigation Unit (DMMU), Zambia Meteorological Department (ZMD) and Ministry of Agriculture $(M \circ A)$ is improved. This will facilitate information sharing, translation into advisory/extension relevant forms and dissemination to intended beneficiaries.

\subsubsection{Improve socio-economic profile of the vulnerable}

This study revealed that the socio-economic profiles of smallholder farmers in the two districts are low particularly, considering the level of income and diversified sources of income. The farmers' level of income is such that they are unable to cover extra household needs upon satisfying important basic ones. The situation leaves them very vulnerable to the impact of climate change. Efforts must be made to improve the livelihood profiles of the smallholder farmers. To this end, public-private pattenership can be pursued in the vulnerable communities to provide more non-farm livelihood opportunities to augment the sources of income for farming households. This will provide a means for livelihood diversification when farmers' major source of livelihood (agriculture) becomes riskier in the face of climate change while augmenting their level of income. That said, social and cultural factors need to be considered so as to avoid failure in the adoption of alternative livelihoods. Why, Cinner et al. [11] have shown that, some social groups (e.g. fishers) that exhibit 'occupational identity' have found it challenging to adopt alternative livelihoods due to the difficulty of re-imagining themselves in livelihood activities other what they have been practicing or associated with.

\subsubsection{Conservation/climate-smart agriculture}

While it is necessary to promote non-farm livelihood activities to diversify livelihoods of smallholder farmers, it is important that their main livelihood activity, agriculture (one of the most vulnerable sectors) is also strengthened against climate change. In view of this, climate-smart forms of agriculture such as conservation agriculture with multiple-use trees should be actively promoted among smallholder farmers. Climate-smart agriculture form of farming that applies soil/water conservation and management techniques, improved and resilient varieties, highquality inputs (better-performing seeds), etc. should be promoted. More so, less expensive small-scale irrigation facilities should be provided in drought-prone areas like AER I to prevent reduced crop yield and losses. Coupling promotion of conservation/climate-smart agricultural practices with adequate extension services will ensure wide adoption of these practices by smallholder farmers.

\subsection{Applicability of social vulnerability index: musings}

Social vulnerability index (SVI) serves the link between science and policy in understanding the social dimensions to climate change vulnerability, planning and development of interventions to improve the adaptive capacity and resilience of social groupings against climate change impacts. Evaluating its applicability is essential to ensuring its greatest validity and utility, and to helping decisionmakers understand not only what the SVI can and does provide, but also what it cannot and does not provide. For researchers, it helps address some vital questions raised on the use of variables (indicators) in assessing climate change vulnerability. For example, how and what variables represent potential driving force(s) for assessing vulnerability $[42,60]$; do variables (indicators) chosen for vulnerability assessment perturb by or interact with each other $[16,60]$; what processes inform selection of variables for vulnerability assessment [60]? Drawing on the results of this study, a reflection on the applicability of the SVI approach in assessing vulnerability to climate change is provided. The reflection touches on the scale of application (spatial and temporal), validity, weighting and aggregation of indicators; and addresses some of the questions raised.

\subsubsection{Scale of applicability (spatial and temporal)}

In terms of scale, the social vulnerability index (SVI) applied in this study as a metric for assessing social dimensions of climate change vulnerability is most appropriate for application at community, district or social groupings (e.g. smallholder farmers) scales. This is not to say that it cannot be applied at household, national or regional levels. Brooks et al. [7], Vincent [55] and Eakin and BojorquezTapia [16] have conducted national- and household-level assessments using similar metric (social vulnerability index). The recommendation is borne out of the consideration for the rate of dynamism of vulnerability factors at the 
household scale, and the low spatial resolution at national and regional scales faced when assessing vulnerability at these scales. For example, a household may be dependent on a climate-sensitive occupation for livelihood hence, its vulnerability to climate change. In the next moment, member(s) of that household may secure additional nonclimate-sensitive livelihood(s). This development would considerably diversify their sources of livelihood and improve their income. The quick change of circumstance would significantly reduce their vulnerability level or move them out of the vulnerability threshold. The reverse may also hold for a hitherto resilient household. This phenomenon is alluded to by Alwang et al. [4] in asserting that households can move in and out of vulnerable states in relatively short periods of time. Such level of dynamism makes SVI application at the household level more suitable on short-medium time scale [16] such as distributing resources or aid to affected households in an emergency following exposure to a climate event such as flood.

On the other hand, creating and applying the SVI at the national or regional scales is faced with the challenge of low spatial resolution thus, masking local variability and subtlety socio-economic and demographic characteristics of communities or social groupings $[4,16,48,55]$. Gbetibouo et al. [23] reiterated this point by asserting that mapping vulnerability at such high scales (e.g. provincial level) may lead to a false sense of precision due to the enormous heterogeneity within provinces and districts related to resource access, poverty level and ability to cope with climate change and variability. Considering the high-level dynamism at the household scale and low spatial resolution at national and regional scales, communities, districts or social groupings constitute an appropriate scale at which the SVI can be applied to assess social vulnerability to climate change. Should the SVI be used for household, national or regional scale vulnerability assessment, the right context, objectives and what it can be used for need to be borne in mind.

\subsubsection{Indicator validity}

The SVI uses indicators to assess vulnerability to climate change. The indicator-based index is widely used $[23,26]$ and provides a means of simplifying complex reality for decision-making. That notwithstanding, question has been raised as to whether indicators "faithfully represent vulnerability processes" (e.g. Rufat et al. [42, p. 478]). The question is basically about whether indicators used in vulnerability assessment accurately represent the intended condition or process - that is, are they valid. Thus, what is indicator validity? Why is validity of an indicator important in assessing social vulnerability to climate change? Indicator validity simply refers to the ability of an indicator to accurately represent what it intends to measure, whether the chosen indicator itself is measurable. A valid indicator is important so that the result of the vulnerability assessment is not misleading and the assertions drawn are not invalid. Some of the factors that can constrain the choice of valid indicators include cost, data availability, easy of measurability and ambiguity.

Consider the case, 'easy of measurability'. An indicator may be valid but may not be easy to measure using standardized measurement. Rufat et al. [42] referred to indicators with psychosocial dimensions which stymie standardized measurement because they are often situationally dependent and may require quantification at scales (e.g. individual, network) different from other indicators. Such indicators cannot be computed from publicly available databases (the challenge of data availability) and may require the use of qualitative methods, targeted surveys, participatory approaches, etc., (cost and measurability challenge). The question is, would that 'valid indicator' be substituted with an 'objective indicator' because of the challenges of cost, data availability and measurability? On the other hand, the case of ambiguity arises when an indicator acts both as an influencer of vulnerability and an enhancer of resilience. As an example, Chen et al. [12] reported Vietnamese migrants' 'lack of acculturation' as strong factors aggravating their social vulnerability, while Vu and Vanlandingham [56] reported 'lack of acculturation' as facilitating close social ties and sharing of resources that allowed them to recover quickly with little outside assistance (i.e. enhancing their resilience rather than increasing their vulnerability). A similar situation was encountered in our study when selecting 'household size' as an indicator for demographic factors that influence vulnerability to climate change. Household size is found to influence vulnerability (e.g. [5, 37, 43, 59]), while it is also associated with reducing vulnerability particularly in agricultural economies where large family size is preferred for improving economic condition [31] and for labour supply. However, considering the context of the study area and the respondents, it was realized that though the many members of the household do contribute labour as unpaid family workers, most these are dependents who do not attract additional external income to the household thereby, increasing the household's vulnerability in the long run. The cases of 'large household size' in our study and the 'lack of acculturation' among the Vietnamese immigrants illustrate the importance of context when identifying valid indicators for vulnerability assessment.

That said, the challenges posed by cost, data availability, measurability and ambiguity should not lead to taking the simple path of 'recycling' indicators (i.e. simply choosing indicators based on their use in previous studies). Developing and testing new indicators and 
their related proxies that best describe their relationship with vulnerability should engage the attention of researchers as an important research need. Other than that, how relevant is an SVI that measures social vulnerability without using the best (valid) indicators? "And to what extent are the assertions valid that, the resultant indicators measure social vulnerability" [42].

\subsubsection{Indicator interrelationships}

In choosing valid indicators, the interrelationships between indicators need to be considered as some of the indicators that may interact in one way or another. To illustrate, consider 'access to climate change information' and 'ownership of TV or radio' used as indicators in this study to assess the influence of social factors on climate change vulnerability. It can be argued that there might be some form of interrelationship between the two indicators. Why, households owning television sets or radio are likely to access information on climate change when climate change-related programmes are aired or broadcast. Therefore, ownership of these devices could imply access to climate change information particularly, in the case of households or individuals who tuned in or listened to such programmes. Even for those who owned the devices and have not the benefits of such programmes may be potential recipients at another time. Similarly, households with diversified sources of income are likely to improve their income level due to the fact that they may hold a primary job and other secondary job(s) that generate additional income for the households. This is not to say that the two indicators for the social and economic factors were duplicative. No, they were distinct in that ownership of television set or radio does not wholly imply access to climate change information. Likewise, access to climate change information may be through other sources such as workshops, community durbars or meetings other than radio or TV.

The point here is to show that there may be interrelationships between these indicators and that some of the indicators may contribute relatively more influence than the other. Considering the potential existence of interrelationship between the indicators, more research needs to be conducted to further explore how social vulnerability determinants interact, and the extent and nature of the relative influence on each other. The results of such research will help in revealing the relative importance of the indicators which will then inform the process of weighting and aggregation, and the need to develop a weighting criterion for the construction of the composite index for measuring social vulnerability to climate change.

\subsubsection{Weighting and aggregation}

The SVI applied in this study employs equal weighting and the additive method of aggregating indicators to form a composite index for the assessment of social vulnerability. Equal weighting and additive method of aggregation (a widely applied approach) in construction of vulnerability index are employed based on the assumption that the indicators operate independently [42] and thus, avoid the process of having to determine the relative importance of disparate indicators [16]. The potential existence of interrelationships between the indicators alluded to in the section on "indicator interrelationships" and as the case may be in the real-world, weighting and an aggregation approach that recognizes indicator interrelationships are strongly favoured. Weighting based on expert judgement is said to be subjective [16], while reductionist statistical approach to weighting indicators is observed to not recognize contextual differences [7]. As such, developing a context-based weighting scheme could be one of the focuses of future research. Until then, an objective compromise would be the use of expert knowledge to identify local context-dependent indicators and subsequently using statistical approaches such as principal component analysis (PCA) or multicriteria decision analysis (MCDA) to select the final indicators and assign them weights.

\section{Conclusion}

This study has investigated social vulnerability to climate change and coping strategies of smallholder farmers in two districts in Zambia. Smallholder farmers in Chirundu district were found to be more vulnerable to climate change than Masaiti district. Low income level, less diversified sources of income and low level ownership of radio or television contributed to the economic and social factors influencing the high vulnerability level of smallholder farmers in Chirundu district. On the other hand, the most engaged coping strategies were planting of drought tolerant species, varying the timing of planting, crop diversification, reliance on government assistance and engagement in non-farm jobs. Various practical recommendations on how to improve the adaptive capacity and resilience of smallholder farmers against climate change impacts related to improving their socio-economic profiles, access to climate change relevant information and promotion of conservation/climate-smart agriculture have been made.

Drawing on the results of this study, the applicability of the SVI approach in assessing social vulnerability to climate change was discussed with the view to ensuring its greatest validity and utility. The discussion focused on the scale of application, and validity, interrelationships, 
weighting and aggregation of indicators. In terms of scale of application, the SVI is most suited for vulnerability assessment at the community, district or social grouping scale than at the household/national/regional scale due to high-level dynamism of vulnerability factors at the household scale, and low spatial resolution at national and regional scales. With regards to indicator validity, there should be a strive towards the use of valid indicators for social vulnerability assessment so that the results are not misleading and the assertions drawn are not invalid. The challenges posed by cost, data availability, measurability and ambiguity should not lead to taking the simple path of 'recycling' indicators. Focused research on indicator interrelationships and their relative importance would help inform the process of contextbased weighting and aggregation in the construction of robust SVI for assessing social vulnerability to climate change.

Acknowledgements The authors are grateful to the European Union through the AFIMEGQ program for providing funds for the study, and to the Copperbelt University for facilitating this research. Thanks to the anonymous reviewers whose critical comments have greatly shaped this paper.

\section{Compliance with ethical standards}

Conflict of interest The authors declare that they have no conflict of interest.

Ethical approval This paper is part of a master's thesis "Assessment of Social Vulnerability of Small-scale Farmers to Climate Change Impacts in Agro-ecological Regions I and III of Zambia" submitted to The Copperbelt University, Zambia. The University ensures that students' dissertation research projects meet high ethical research standards and do not violate the rights of participants involved in the research.

\section{References}

1. Adger NW (1999) Social vulnerability to climate change and extremes in coastal Vietnam. Pergamon 27(2):249-269

2. Adger WN, Brown K, Tompkins EL (2004) Why do resource managers make links to stakeholders at other Scales? Tyndall Centre Working Paper No 65. Norwich, Tyndall Centre for Climate Change Research

3. Adger WN, Barnett J, Brown K, Marshall N, O'Brien K (2013) Cultural dimensions of climate change impacts and adaptation. Nat Clim Change 3:112-117

4. Alwang J, Siegel PB, Jorgensen SL (2001) Vulnerability: a view from different disciplines. Social Protection Discussion Paper No. 0115. Human Development Network. The World Bank

5. Blaikie P, Cannon T, Davis I, Wisner B (1994) At risk: natural hazards, people's vulnerability, and disasters. Routledge, New York

6. Braun B, Aßheuer T (2011) Floods in megacity environments: vulnerability and coping strategies of slum dwellers in Dhaka/ Bangladesh. Nat Hazard 58(2):771-787
7. Brooks N, Adger WN, Kelly PM (2005) The determinants of vulnerability and adaptive capacity at the national level and the implications for adaptation. Glob Environ Chang 15:151-163

8. Burton I, Kates RW, White GF (1993) The environment as hazard, 2nd edn. Oxford University Press, New York

9. Burton I, Huq S, Lim B, Pilifosova O, Schipper EL (2002) From impacts assessment to adaptation priorities: the shaping of adaptation policy. Clim Policy 2:145-159

10. Cannon T (1994) Vulnerability analysis and the explanation of natural disasters. In: Varley A (ed) Disasters development and environment. Wiley, Chichester, pp 13-30

11. Cinner JE, Adger WN, Allison EH, Barnes ML, Brown K, Cohen PJ, Gelcich S, Hicks CC, Hughes TP, Lau J, Marshall NA, Morrison TH (2018) Building adaptive capacity to climate change in tropical coastal communities. Nat Clim Change 8:117-123

12. Chen A, Keith V, Leong K, Airriess C, Li W, Chung K, Lee C (2007) Hurricane Katrina: prior trauma, poverty and health among Vietnamese-American survivors. Int Nurs Rev 54(4):324-331

13. Cutter SL, Boruff BJ, Shirley WL (2003) Social vulnerability to environmental hazards. Soc Sci Q 84:242-261

14. Donatti $\mathrm{Cl}$, Harvey $\mathrm{CA}$, Martinez-Rodriguez MR, Vignola R, Rodriguez CM (2019) Vulnerability of smallholder farmers to climate change in Central America and Mexico: current knowledge and research gaps. Clim Dev 11(3):64-286

15. Dumenu WK, Obeng EA (2016) Climate change and rural communities in Ghana: social vulnerability, impacts, adaptations and policy implications'. Environ Sci Policy 55:208-217

16. Eakin H, Bojorquez-Tapia LA (2008) Insights into the composition of household vulnerability from multicriteria decision analysis. Glob Environ Change 18:112-127

17. Ellis F, Allison E (2004) Livelihood diversification and natural resource access. FAO Livelihood Support Programme (LSP), Working Paper 9. FAO, Rome

18. Eriksen S, Klein R, Ulsrud K, Naess L, O'Brien K (2007) Climate change adaptation and poverty reduction: key interactions and critical measures. GECHS Report 2007. University of Oslo, Oslo

19. FEWSNET (2014) Map of livelihood zones in Zambia. Famine Early Warning Systems Network, Washington

20. Ford JD, Keskitalo ECH, Smith T, Pearce T, Berrang-Ford L, Duerden F, Smit B (2010) Case study and analogue methodologies in climate change vulnerability research. Wiley Interdiscip Rev Clim Change 1(3):374-392

21. Fumpa-Makano R (2011) Forests and climate change: integrating climate change issues into National Forest Programmes and Policy Frameworks. Background Paper for the National Workshop, Zambia. FAO and the Government of the Republic of Zambia. Lusaka, Zambia

22. Gbetibouo GA, Ringler C (2009) Mapping South African farming sector vulnerability to climate change and variability: a subnational assessment. In: The 2009 Amsterdam Conference on the Human Dimensions of Global Environmental Change. Earth System Governance: People, Places and the Planet. Amsterdam, 2-4 December 2009

23. Gbetibouo GA, Ringler C, Hassan R (2010) Vulnerability of the South African farming sector to climate change and variability: an indicator approach. Nat Resour Forum 34:175-187

24. Government of the Republic of Zambia (GRZ) (2013) Zambia's intended nationally determined contribution (INDC) to the 2015 agreement on climate change. http://www.agriculture.gov.zm/ index.php?option=com_content\&view=article\&id=195:thefarmer-input-support-programme-and-the-food-reserve-agenc $y \&$ catid $=100 \& \mid$ temid $=1546$. Accessed 10 Nov 2018

25. Hamazakaza P (2015) Good agricultural adaptation: Findings from research in maize, sorghum and cotton based farming system in Zambia. Kulima Integrated Development Solutions, Kwabe 
26. Hebb A, Mortsch L (2007) Floods: mapping vulnerability in the Upper Thames Watershed under a changing climate. In: CFCAS project: assessment of water resources risk and vulnerability to changing climatic conditions. Project Report XI. University of Western Ontario, London

27. IPCC (2001) Climate change 2001: impacts, adaptation, and vulnerability. Contribution of Working Group II to the Third Assessment Report. Cambridge University Press, Cambridge

28. Kelly P, Adger W (2000) Theory and practice in assessing vulnerability to climate change and facilitating adaptation. Clim Change 47:325-352

29. Mulenga BS (2010) Climate change in Zambia: opportunities for adaptation and mitigation through Africa Bio-carbon initiative. Center for International Forest Research, Southern Africa Regional Office, Lusaka

30. Morrow BH, Enarson E (1994) Making the case for gendered disaster research. Paper presented at the 13th World Congress of Sociology, 19 July, Bielefeld, Germany

31. Morrow BH (1999) Identifying and mapping community vulnerability. Disasters 23(1):11-18

32. Ministry of Tourism, Environment and Natural Resources (MTERN) (2007) Formulation of the National Adaptation Plan of Action (NAPA) on climate change. Final Report. MTENR. https:// www.adaptation-undp.org/resources/assessments-and-backg round-documents/zambia-national-adaptation-programmeaction-napa. Accessed 10 Nov 2018

33. Ministry of Tourism, Environment and Natural Resources (MTERN) (2010) National climate change response strategy. https://www.adaptation-undp.org/resources/naps-least-devel oped-countries-Idcs/zambia\%E2\%80\%99s-national-climatechange-response-strategy-\%E2\%80\%93. Accessed 10 Nov 2018

34. Ministry of Lands, Natural Resources and Environment Protection (MLNREP) (2016) National policy on climate change. Ministry of National Development Planning, Government of the Republic of Zambia

35. ND-GAIN (2019) The ND-GAIN Country Index, 2017: Zambia profile. Notre Dame Global Adaptation Initiative. University of Notre Dame. https://gain.nd.edu/our-work/country-index/rankings/. Accessed 05 May 2019

36. Nhemachena C, Hassan R (2007) Micro-level analysis of farmers' adaptation to climate change in Southern Africa. IFPRI Discussion Paper 00714. Centre for Environmental Economics and Policy in Africa

37. Nkondze MS, Masuku MB, Manyatsi A (2013) Factors affecting households vulnerability to climate change in Swaziland: a case of Mpolonjeni area development programme (ADP). J Agric Sci 5:108-122. https://doi.org/10.5539/jas.v5n10p108

38. O'Brien K, Eriksen S, Nygaard LP, Schjolden A (2007) Why different interpretations of vulnerability matter in climate change discourses. Clim Policy 7:73-88

39. Oyekale AS, Oladele OI (2012) Determinants of climate change adaptation among cocoa farmers in southwest Nigeria. J Food Agric Environ 10(3-4):1562-1567

40. Parry M, Carter T (1998) Climate impact and adaptation assessment: a guide to the IPCC approach. Earthscan, London

41. Puente S (1999) Social vulnerability to disaster in Mexico City. In: Mitchell JK (ed) Crucibles of hazard: mega-cities and disasters in transition. United Nations University Press, Tokyo, pp 295-334

42. Rufat $S$, Tate E, Burton GC, Maroof SA (2015) Social vulnerability to floods: review of case studies and implications for measurement. Int J Disaster Risk Reduct 14:470-486

43. Shewmake $S$ (2008) Vulnerability and the impact of climate change in south Africa's Limpopo River Basin. IFPRI Paper 00804. IFPRI, Washington, DC
44. Singh NP, Bantilan C, Byjesh K (2014) Vulnerability and policy relevance to drought in the semi-arid tropics of Asia: a retrospective analysis. Weather Clim Extrem 3:54-61. https://doi. org/10.1016/j.wace.2014.02.002

45. Smith JB, Lenhert SS (1996) Climate change adaptation policy options. Clim Res 6:193-201

46. Smit B, Wandel J (2006) Adaptation, adaptive capacity and vulnerability. Glob Environ Change 16:282-292

47. Smith B, Burton I, Klein RJT, Wandel J (2000) An anatomy of adaptation to climate change and variability. Clim Change 45:223-251

48. Thornton PK, Jones PG, Alagarswamy G, Andresen J, Herrero M (2010) Adapting to climate change: agricultural system and household impacts in East Africa. Agric Syst 103(2):73-82

49. Tompkins EL, Hurlston $L$ (2005) Natural hazards and climate change: what knowledge is transferable? Tyndall Centre Working Paper 69. Tyndall Centre for Climate Change Research, Norwich

50. Turner BL, Kasperson RE, Matson PA, McCarthy JJ, Corell RW, Christensen L, Eckley N, Kasperson A, Luers A, Martello ML, Polsky C, Pulsipher A, Schiller A (2003) A framework for vulnerability analysis in sustainability science. Proc Natl Acad Sci 100:8074-8079

51. United Nations Development Programme (UNDP) (2013) Millennium development goals. Provincial profile: Lusaka. Lusaka, Zambia

52. United Nations Development Programme (UNDP) (2013) Millennium development goals. Provincial profile: Copperbelt. Lusaka, Zambia

53. United Nations Environment Programme (UNEP) (2001) Vulnerability indices: climate change impacts and adaptation. UNEP Policy Series 3. UNEP, Nairobi

54. Vincent $K$ (2004) Creating an index of social vulnerability to climate change for Africa. Tyndall Centre Working Paper No. 56. Tyndall Centre for Climate Change Research, Norwich

55. Vincent $K$ (2007) Uncertainty in adaptive capacity and the importance of scale. Glob Environ Change 17:12-24

56. Vu L, Vanlandingham MJ (2012) Physical and mental health consequences of Katrina on Vietnamese immigrants in New Orleans: a pre-and post-disaster assessment. J Immigr Minor Health 14(3):386-394

57. Watts MJ, Bohle HG (1993) The space of vulnerability: the causal structure of hunger and famine. Prog Hum Geogr 17:43-67

58. Wehbe MB, Eakin H, Santos C, Civitaresi HM, Seiler RA, Vinocur MG (2003) Social methods for assessing agricultural producers' vulnerability to climate variability and change based on the notion of sustainability. In: Presentation at the open meeting of the Global Environmental Change Research Community, Montreal, Canada, 16-18 October

59. Wongbusarakum S, Loper C (2011) Indicators to assess community level social vulnerability to climate change: an addendum to SocMon and SEM Pasifika Regional socioeconomic monitoring guidelines

60. Younus M, Kabir M (2018) Climate change vulnerability assessment and adaptation of Bangladesh: mechanisms, notions and solutions. Sustainability 10(11):4286. https://doi.org/10.3390/ su10114286

Publisher's Note Springer Nature remains neutral with regard to jurisdictional claims in published maps and institutional affiliations. 